\title{
Rethinking the Roles of Professionalism and Administrative Acts in Organisations
}

\author{
Given Mpolokeng Ramajoe \\ Tshwane University of Technology, Pretoria, South Africa \\ Correspondence should be addressed to: Given Mpolokeng Ramajoe; RamajoeGM@tut.ac.za
}

Received date: 2 August 2013; Accepted date: 26 May 2014; Published date: 24 April 2015

Academic Editor: Kamarulzaman Ab. Aziz

Copyright (C) 2015 Given Mpolokeng Ramajoe. Distributed under Creative Commons CC-BY 4.0

\begin{abstract}
Organisations depend on the administrative process to carry out their goals and objectives, for the purposes of competitiveness and sustainability. As such, administrative functions are considered to be critical in the organisations. Hence, many organisations have little or no "room" for the malfunctioning of their administrative activities. There are a number of challenges that organisations encounter, one of the most critical of the challenges is to align employees' interest with the organisational values and goals. This happens at both public and private organisations, at different levels of the organisational structure. The challenges of administrative process are inevitably associated to workplace Professionalism, which has become a fundamental factor for cultural built and prerequisite for Organisational success or failure. Some Organisations are aware of the administrative challenges, and others are not. Of those Organisations that are aware of the challenges, some of them do not seem to understand the gravity and depth of the impact it has on their growth, sustainability and competitiveness. Also, some of the organisations experience difficulty in attempt to manage the professional and administrative challenges within their environment. This is the motivation for this study. This paper presents the result from an interpretive case study, and the framework that was developed. The aim of the framework, Managing Professionalism and Administrative Framework (MPAF) is to guide managers and other employees in the management of professional acts and administrative activities in their Organisations.
\end{abstract}

Keywords: Organisation, Management, Professionalism, Administrative, Case Study, Framework

\section{Introduction}

In many organisations, employees and employers rely on interaction and communication to carry out their professional and administrative roles and responsibilities, in achieving common goals and objectives. Professionalism in an administrative environment is fostered by communication and interactions that happen between, employee-to-employee, and employee-employer. The communication and interactions are considered to be of suitable beliefs and standards to employees who are willing to accept and implement what has been communicated (Akhtar-Danesh, Baumann, Kolotylo, Lawlor, Tompkins \& Lee, 2013:248). 
In accordance with the code of ethics of many organisations, individuals and groups are expected to be worthy of trust, and to maintain confidentiality in the administrative management environment. Distinctive professional values and/or moral obligations could apply to a particular work environment, limiting excessive competition and encouraging cooperation. In effect, professionalism is emphasised to persuade employees, practitioners and other workers to perform in ways which the organisation deems appropriate, effective and efficient (Evetts, 2003:395).

Hipps (2010:2) argued that for a business is to be successful, it is imperative for employees to acquire and practise appropriate principles of work behaviour (i.e. competence, conduct, accountability and avoiding conflicts of interest)."Competence" includes knowledge and the application of new techniques and ideas. Those who are competent are generally able to multi-task easily, using a variety of skills, including superior time management. These individuals maintain respect for others and are able to utilise appropriate resources in the work environment. They are responsible leaders and capable of supervising and providing guidance to others.

All Organisations and their employees are expected to conduct themselves appropriately, within the organisational code of conduct. Such proper and acceptable conduct requires employers and employees to adhere to the organisation's basic etiquette guidelines. It also includes discretion with regard to sensitive content, maintaining a "team environment", and complying with all legislation, regulations and procedures (Phipps, 2010:2).

For professionalism to flourish, all practice should reflect a spirit of openness, enhanced by the conviction that individual professional skills would routinely be open to inspection and evaluation (Freidson, 1994:196). Along the same line of argument, Manning (2006:15) maintained that individual professional skills will subtly help managers to demonstrate individuality. However, such individual skills would always recognise norms of behaviour that will not upset others.

Based on the identified challenges with professionalism within administrative environment, this study was carried out. The objective of the study was to understand and examine the impact of professionalism on administrative processes and activities in the organisations. The findings from the study are presented in this paper. The remainder of this paper is divided into four main sections. The first and second sections present literature review on administration and management, and the research methodology through which the study was carried out respectively. The third section covers the analysis of the data. In the fourth section, the framework that emanated from the findings was discussed. Finally, a conclusion was drawn.

\section{Administration and Management in Organisations}

Administrative processes are fostered through communication of suitable beliefs and standards to employees who are willing to accept and implement them (Akhtar-Daneshet al, 2013:248). Individuals and groups within Organisations are expected to be worthy of trust, and to maintain confidentiality in the administrative management of the environment. According to Ferreira, Erasmus and Groenewald (2009:3), administrative management encompasses the processes and resources required to collect, manipulate, maintain, protect and retrieve all information Organisations require.

Management in organisation has never been easy, it actually gets tougher. Meyer and Kirby (2010:38-46) argued that most managers want their subordinates to act in a socially acceptable manner. The fact that they often act in a contrary or unprofessional manner, is in part due to the many and varied demands made of them. The pressures come from all directions, and it often seems impossible to 
do enough. According to Stratton, Mitstifer and $\mathrm{Nu}(2010: 2)$, to be professional is to have a passion for accountability, responsibility, devotion to service, commitment to a mission, openness to new ideas, and continuous learning. Antezana (2010:1) describes professionalism in an organisation as based on factors such as effective and ethical leadership, courage, integrity and sensitivity in leadership, and a leader's belief in creating and sharing an ethical vision with employees.

According to Tau and Mathebula (2008:353), professionalism refers to being qualified, competent, efficient and masterly. It requires commitment to an ethic of product and service quality, and to being innovative. It is argued to be most effective when it begins at the top and proceeds downwards throughout the organisational structure to become part of the business philosophy. Distinctively, professionalism imbues its practitioners with a code of ethics and internalised standards (Mafunisa, 2001:324-339). Distinctive professional values and/or moral obligations could apply to a particular work environment, limiting excessive competition and encouraging cooperation. In effect, professionalism is emphasised to persuade employees, practitioners and other workers to perform in ways which the organisation deems appropriate, effective and efficient (Evetts, 2003:395-415).

The United Nations (1997:6) clarified the term professionalism, stating that professionalisation in administration has been characterised by an adherence to the merit system, in order to task specialisation to economy, and the effectiveness achieved through political neutrality. Professionalism encompasses professional standards, values, and ethics rather than political or other criteria.

Within the context of professionalism and how organisations understand it through their definition in the code of conduct, employers and employees are expected to conduct themselves appropriately. Such proper conduct includes both knowledge and following basic etiquette guidelines. It also includes discretion with regard to sensitive content, maintaining a "team environment", and complying with all legislation, regulations and procedures (Phipps, 2010:2).

\section{Research Methodology}

The social context and complex nature of the study require the use of both qualitative and quantitative research methods (Amaratunga, Baldry, Sarhar \& Newton, 2002:17; De Vos, Strydom, Fouché \& Delport, 2002:79). It helps as the two methodological paradigms are not in opposition to each other, but in complementarity. David and Sutton (2004:35) described Quantitative research as an enquiry into a social or human problem, by way of statistical procedures, and Qualitative research usually emphasises statements instead of quantification and analysis. Interpretive techniques are followed to describe and translate meaning in a social world (Cooper \& Schindler, 2006:196). The qualitative researcher is concerned with understanding a situation rather than explanation.

Quantitative research focuses on variables that have to be analysed statistically (Oates, 2006:245). In quantitative research, the relationship between variables or numbers is expressed in terms of correlations, relative frequencies or differences. The quantitative research method was used in this study to determine the extent to which public and private Organisations adhere to the components of professionalism in their administrative environments.

Two cases, Private and Public organisations were used in the study. Yin (2009) argued the use of multiple case studies is strong, and by implication, adds more credibility to the study. The two organisations were selected based on accessibility, and proximity.

The open-ended technique was used to collect qualitative data. According to Remler \& Van (Ryzin, 2011), the openended technique allows participants to 
provide answers in their own words and as detailed as they consider appropriate. In obtaining the quantitative data, the questionnaire approach was employed.

Blaikie (2009:205) states that "the most commonly used quantitative datagathering methods in the social sciences are undoubtedly the self-administered questionnaire and the structured interview, both of which keep the researcher at a distance from actual social processes". This method helps to overcome misunderstandings and misinterpretations of words and questions (Bless, HigsonSmith \& Kagee, 2006:120). The participants' answers are clear because the interviewer can ensure that the participants understand the questions correctly. Questionnaires were designed to elicit useful information for analysis (Babbie, 2005:253).
A total of 200 personnel participated in the study, from both qualitative and quantitative approaches. As shown in Table 1 below, "Ques" and "Interv" represent quantitative and qualitative data respectively. For the purposes of this study, interviews were conducted, a questionnaire with closed-ended questions was used in complementarity to collect data for analysis. This enabled inputs from management, supervisors, administrators and students, expressing their views on professionalism in the administrative environment.

Criteria were used to identify and select the participants. The selection criteria included atleast 5 years of profession service in the organisation, knowledge organisational core businesses, and responsible or involved in administrative activities in the organisation.

Table 1: Participants

\begin{tabular}{|l|l|l|l|l|l|l|l|l|l|}
\hline \multirow{2}{*}{ Organisations } & \multicolumn{2}{l|}{ Managers } & \multicolumn{2}{l|}{ Supervisors } & \multicolumn{2}{l|}{ Admin } & \multicolumn{2}{l|}{ Students } \\
\cline { 2 - 10 } & $\begin{array}{l}\text { Que } \\
\text { s. }\end{array}$ & Interv & $\begin{array}{l}\text { Ques } \\
.\end{array}$ & Interv & Ques & $\begin{array}{l}\text { Inter } \\
\text { v }\end{array}$ & Ques & $\begin{array}{l}\text { Inter } \\
\text { v }\end{array}$ & l \\
\hline Public sector & 10 & 5 & 14 & 7 & 77 & 10 & 5 & 2 & 130 \\
\hline Private sector & 6 & 4 & 5 & 2 & 45 & 7 & & 1 & 70 \\
\hline TOTAL & $\mathbf{1 6}$ & $\mathbf{9}$ & $\mathbf{1 9}$ & $\mathbf{9}$ & $\mathbf{1 2 2}$ & $\mathbf{1 7}$ & $\mathbf{5}$ & $\mathbf{3}$ & $\mathbf{2 0 0}$ \\
\hline
\end{tabular}

The data were analysed, using the interpretive method. Interpretive techniques are followed to describe and translate meaning in a social world (Cooper \& Schindler, 2006:196).

\section{Data Analysis}

The primary goal of the study was to develop a framework which could be used to guide the management of administrative processes and professional acts in organisations. Based on the goal, the objectives of the study were articulated, which were to understand and examine the impact of professionalism on administrative processes and activities in the organisations. In order to achieve the goal and objectives, three questions were formulated. The questions included: Which factors constitute professional and unprofessional behaviour in
Organisations?; Which factors cause professional and unprofessional behaviour in Organisations?; and What is the impact of both professional and unprofessional behaviour in Organisations?

The research questions were used to elicit answers from different respondents, form sets of data. The data were interpretively analysed and presented as follows:

\section{Which factors constitute professional and unprofessional behaviour in Organisations?}

The respondents emphasised, on one hand, that the factors which manifest themselves into professional act include leadership style, commitment, responsibility, accountability and trust as well processes such structured systems, orientation and governance that influenced the objectives, 
activities, roles and functions of the organisation. On another hand, the respondents were critical in their views that factors that constituted unprofessional behaviour included insubordination, nepotism, favouritism and substance abuse.

In the absence of defined policies, standards, and an acceptable code of conduct, unprofessional behaviour posed a challenge to Organisations that functioned without proper mechanisms in place. The significance of professionalism is based on people and processes in an organisation, how employees and managers relate to each other, and the implementation of structured systems in the organisation. The interdependency of factors such as openness, interpersonal relations, networks, structured systems, orientation and awareness, and governance help managers and employees to manage the activities of an organisation properly.

\section{Which factors cause professional and unprofessional behaviour in Organisations?}

This question indicated the importance of factors such as leadership and governance in Organisations. Without an acceptable leadership style or sound governance, an organisation could become confused. It was found that employees who were familiar with their organisation's policies and procedures were seldom inclined to unprofessional conduct. Professionalism follows naturally in an organisation whose managers are trusted, committed, and accountable. This kind of leadership encourages employees to align their individual interests with those of the organisation.

Unprofessional behaviour is usually caused by managers who instruct employees to perform duties beyond their job descriptions and the principles and polices of the organisation. Poor communication, personal difficulties and personality conflicts also affect the roles and responsibilities of employees.

\section{What is the impact of both professional and unprofessional behaviour in Organisations?}

Professional behaviour has a positive impact on organisational activities. It is open and there is consultation, so that employees feel committed and responsible for their actions and decisions. When managers lead professionally, the roles and functions of employees become clearer and they almost automatically adhere to the set policies, standards and the accepted code of conduct. All efforts consequently focus on achieving the organisation's objectives, which in turn facilitate governance. Unprofessional behaviour creates tension, insubordination and favouritism, all of which have a negative impact and eventually destroy the organisation's image and reputation.

In summary, in order to achieve stated organisational goals, openness, a structured system, interpersonal relations, orientation and awareness, networks and governance were found to be determining factors and drivers in the professional and unprofessional behaviours of employees in Organisations. Sometimes processes are introduced to achieve organisational objectives or personal goals. Employees enact processes that define the scope and limit of organisational activities. Effective communication is essential in motivating employees to adhere to the standards set by management. When there are no standards there is not consistency, productivity, quality or effective performance.

\section{Framework for Managing Professionalism and Administrative Environment}

This section presents the managing professionalism and administrative framework (MPAF) that is based on the analysis of this study's data. The framework, or MPAF as shown in Figure 1, was developed after the interpretation and discussion of the study's findings. As mentioned before, data were collected from both the public and private sectors. 
The MPAF is primarily aimed at understanding the different factors that cause professional and unprofessional behaviour in Organisations. The framework's intention is to guide and manage professional and administrative activities in Organisations. The discussion that follows Figure 1 should be read in conjunction with the figure to gain a better understanding of the factors that influence the management of professionalism in an administrative environment.

Figure 1 illustrates that the MPAF consists of six main components, namely people, processes, the organisational culture, communication, governance and leadership.

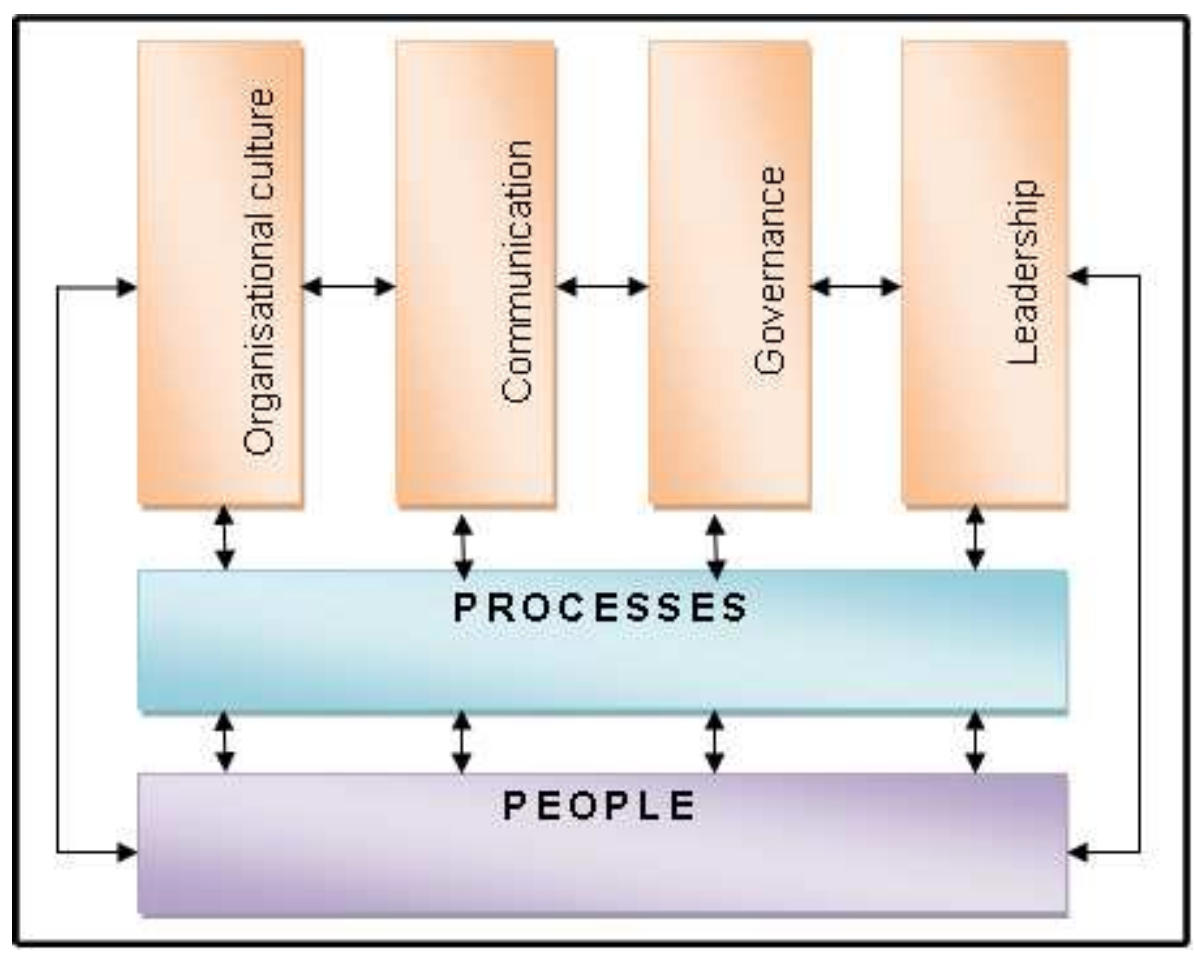

Figure 1: Professionalism and Administrative Framework (PAF)

\section{i. People}

Organisations exist because of people, making the relevance of individuals significantly critical. Consequently, the events and activities of Organisations are designed for people and by people. This makes the human component of Organisations critical. Managing people is a complex task, hence professional as well as unprofessional performance. People have different interests that elicit and guide their actions in space and time. These actions may be intended or unintended, but either has consequences for the organisation and other people. Unfortunately, no organisation has absolute control over its employees. Hence, the management of people's activities and the events in which they become involved is of the utmost importance.

\section{ii. Processes}

Processes are the expression of organisational values, norms, and legitimate activities. Moreover, processes are ongoing, and require skills to be used by the people and for people in an organised environment. Processes can become cumbersome, depending on how people interpret and apply them. Consequently, it can be used to enable or constrain activities and events. This is the primary reason why processes are considered to be a significant component in managing administrative actions as either professional or unprofessional. 


\section{iii. Organisational Culture}

Organisational culture refers to the underlying values and beliefs that dictate the behaviour of employees. This culture has a potent effect on an organisation's wellbeing. An organisation's culture affects the way in which employees interact. Their interaction manifests in networks that share collective behaviour patterns and meanings that provide a sense of order so that employees are fully aware what is expected of them.

\section{iv. Communication}

Communication is an essential aspect of an organisation's success or failure. Communication shapes and guides both professional and unprofessional actions that are significant to the organisation's performance. Relevant communication disseminates information on policies and procedures. When good communication is considered a fundamental principle, it strengthens the organisation's strategic direction. Poor communication weakens this strategic direction and affects relations between employees and their managers.

\section{v. Governance}

The importance of governance is to establish standards, principles, policies and processes for business practices and activities. These elements of governance are critical to professional management and administration because they enforce policies, standards and a code of conduct, and encourage respect for set procedures in order to achieve the organisation's objectives.

The absence of these elements of governance would have a significant impact on processes and procedures and misdirect all efforts at enforcing quality products and services. The absence of proper governance provides latitude to managers to issue instructions that are contrary to the policies of the organisation.

\section{vi. Leadership}

Leadership depends on the organisational orientation and established culture. Leadership enables employees to maintain and nurture their organisation's culture. When a particular leadership style has been established, it becomes the professional norm for conduct and communication between managers and their subordinates.

\section{Conclusion}

This paper empirically unveiled the factors which manifest, directly or indirectly, dictate acts of administrative manoeuvring professionalism in organisations. The findings from the study as presented in this paper are intended to help both employers and employees to have a deeper understanding of the factors that cause and influence professional and unprofessional behaviours in the Organisations. The framework, Managing Professionalism and Administration Framework (MPAF) is intended to assist the employers and the managers in addressing some of the challenges relating to professional and unprofessional acts, which are encountered in the organisations.

Following the MPAF, the management will have a better understanding of why certain things happen in the way that they do, in the context of professional acts and administrative processes, which sometimes have consequences on the organisation's growth and competitiveness. The framework facilitates understanding between the employees and employers, towards achieving common goals.

Also, the paper provokes academic thought for further research and development. This could be of benefit to both postgraduate candidates and academia in the areas of research, training, and development.

\section{References}

1.Akhtar-Danesh, N., Baumann, A., Kolotylo, C., Lawlor, Y., Tompkins, C. \& Lee, R. (2013). "Perception of Professionalism among Nursing Faculty and Nursing Students," 
Western Journal of Nursing Research, 35 (2), 248-271.

2.Amaratunga, D., Baldry, D., Sarshar, M. \& Newton, R. (2002). "Quantitative and Qualitative Research in the Built Environment: Application of "Mixed" Research Approach," Work Study, 51(1), 17-31.

3.Antezana, H. (2010). 'What is Professionalism in the Workplace,' [Online]. Available at: http://www.profimpressions.co.za/index.p hp?option=com_content\&view=article\&id= [Accessed 19 May 2010]

4.Babbie, E. (2005). 'The Basics of Social Research,' 2nd ed. Belmont: Thomson Wadsworth.

5.Babbie, E. (2005). 'The Basics of Social Research,' 3rd ed. Wadsworth: Thomson Learning.

6.Blaikie, N. (2009). Designing Social Research, Cambridge: Polity Press.

7.Bless, C., Higson-Smith, C. \& Kagee, A. (2006). Fundamentals of Social Research Methods: An African Perspective, 4th ed. Cape Town: Juta.

8.Cooper, D. R. \& Schindler, P. S. (2003). 'Business Research Methods,' 8th ed. New York: McGraw-Hill/Irwin.

9.David, M. \& Sutton, C. D. (2004). Social Research: The Basics, London: Sage.

10.De Vos, A. S. (2002). Research at Grassroots: For the Social Science and the Human Service Professions, 2nd ed. Pretoria: Van Schaik.

11.Evetts, J. (2003). "The Sociological Analysis of Professionalism: Occupational Change in the Modern World," International Sociology. [Online]. 18(2), Available at: http://iss.sagepub.com/content/18/2/395 [Accessed 24 August 2010]

12.Freidson, E. (1994). Professionalism
Reborn: Theory, Prophecy and Policy, Chicago: University of Chicago Press.

13.LeCompte, M. \& Preissle, J. (1993). 'Ethnography and Qualitative Design in Educational Research,' London: Academic Press Inc.

14.Leedy, P. D. \& Ormrod, J. E. (2005). 'Practical Research: Planning and Design,' 8th ed. Columbus: Prentice Hall.

15.Mafunisa, M. J. (2001). "Professionalism: The Ethical Challenge for Municipal Employees," South African Journal for Public Administration and Management, 36(4), 329 - 339.

16.Manning, E. (2006). Up the Corporate Ladder: A Guide to Professionalism in the Workplace, Paarl: Paarl Print.

17.Mouton, J. (2001). 'How to Succeed in Your Master's and Doctoral Studies: A South African Guide and Resource Book,' Pretoria: Van Schaik.

18.Muijs, D. (2004). Doing Quantitative Research in Education with SPSS, London: Sage.

19.Nardi, P. M. (2003). 'Doing Survey Research: A Guide to Quantitative Methods,' Chicago: Pearson Education.

21.Northouse, P. G. (2009). 'Leadership: Theory and Practice,' 5th ed. London: Sage.

22.0'Leary, Z. (2010). 'The Essential Guide to Doing Research,' London: Sage.

23.0ates, B. J. (2006). Researching Information Systems and Computing, London: Sage Publications, Ltd.

24.Phipps, N. (2010). 'Professionalism in the Office,' Self help articles [Online]. [Accessed 23 August 2010]

25.Remler, D. K. \& Van Ryzin, G. G. (2011). 'Research Methods in Practice: Strategies for Description and Causation,' London: Sage.

26.Schindler, P. S. \& Cooper, D. R. 
(2006). Marketing Research, New York: McGraw-Hill.

27.Stratton, S. S., Mitstifer, D. I. \& Nu, K. O. (2010). "Notes for Professionalism and Career Networking," [Online]. Available from:

http://www.kon.org/pdf/Notes_for_Profes sionalism.pdf [Accessed19 May 2010]
28.Tau, M. \& Mathebula, D. (2008). "Capacitating the State through the Promotion of Sound Ethics and Professionalism within the Teaching Profession," Journal of Public Administration. [Online]. 43(3.1), Available at:

http://ol.up.ac.za/upspace/bitsream/2263 /8663/1/Tau_Capacitating(2008).pdf [Accessed 24/08/2010] 